\title{
The Development of British Civil Servants Classification System for China's Enlightenment
}

\author{
Song Wang \\ College of Public Management Administration, Tianjin University of Commerce, Tianjin, China
}

Email address:

447874148@qq.com

\section{To cite this article:}

Song Wang. The Development of British Civil Servants Classification System for China's Enlightenment. Humanities and Social Sciences. Vol. 4, No. 6, 2016, pp. 161-165. doi: 10.11648/j.hss.20160406.15

Received: November 14, 2016; Accepted: December 5, 2016; Published: December 7, 2016

\begin{abstract}
The classification system of civil servants is of vital to the entire civil service system; the civil service system has a far-reaching impact on the country's stability and orderly operation. Therefore, the improvement of the civil service classification system has a positive effect on the ability of national governance. Britain is the most representative modern governance country which based on grade. UK's grade classification system had gradually developed to a classification system of civil servants which combines grade and job classification. Studying the history of the development of grade classification of British civil servants has important implications on the classification system of civil servants in China. The enlightenment indicates the direction of the development of the civil servants. Through comparing, we can sum up some useful aspects of Chinese civil servants classification, and strengthen them. And development direction for the future of China's public servants to make some beneficial exploration.
\end{abstract}

Keywords: Civil Service Classification, Grade, Position

\section{The Status of the Chinese Civil Service Classification System}

See from China's current civil service classification system, China merely has the division of job categories which Consist of comprehensive management, professional and technical categories, administrative law enforcement, judges and prosecutors. The fifteenth Civil service law provisions: the state sets up civil service positions in accordance with the classification of the civil service sequence. Then the corresponding position sequence is a series of comprehensive management, professional and technical class sequence, the administrative law enforcement class sequence, the judge and prosecutor class sequence. The job sequence consists of two basic elements which is job level posts and job classes. Each post sequence corresponds to a position of leadership positions, leadership positions sequence and their levels are unified and from the level of country to the level of deputy township section and nearly ten job level. The sequences of duties level of comprehensive management class of non-leadership positions are eight which is from inspector to clerk. The above is our country's current civil service classification system. It is oriented by position classification and absorbs the reasonable factors of the classification system at the same time. Finally construct the position classification system with Chinese characteristics. Choose the British civil servants classification system development paths, Because of the ancient Chinese civil servants classification system are also classified according to taste is given priority to, This kind of similar path is more advantageous to contrast, selecting, and learning.

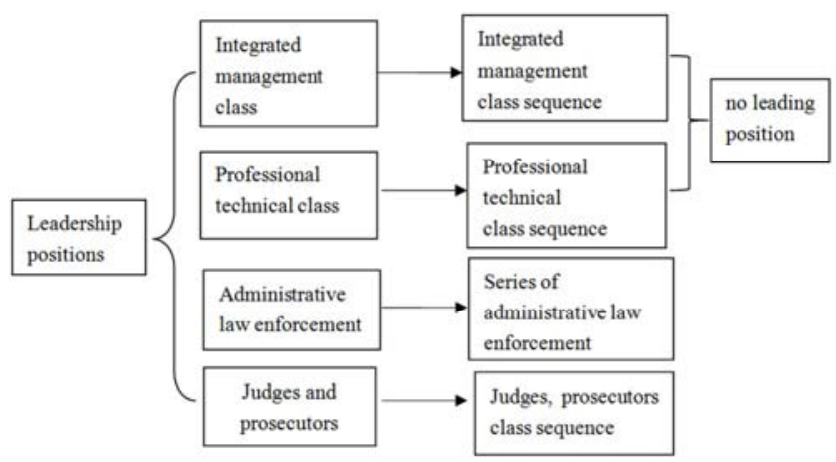

Fig. 1. China civil service classification system. 


\section{The Development of the British Civil Service Classification System}

British civil service classification system is developed with the grade classification system. For a mature system, on the one hand, has a historical inheritance and the accumulation; on the other hand, must adapt to the development of the specific circumstances of the region. Based on these two points, we can form the civil service classification system which is suitable for the local area. At the same time, as long as it is suitable for their own business development and can run well, civil service system will be a good system.

\subsection{The Selection Criteria is Given Priority to with Generalists}

Throughout the development history of British civil service classification system, it can be seen that this is a "generalist" "professionals" system reform and development path. In mid nineteenth Century, British civil service system established, in the context of the times, the size of government was smaller than now and government affairs wasn't more fine than today, so "generalist" talents with high degree were especially suitable for civil service appointment. At that time, people thought that civil servants should be knowledge broadcasting and extraordinary talents who have many aspects of accomplishment. In this period, classification system of civil servants highlights the British classification system characteristics based on grade classification.

In 1870 the British privy council decree, The civil service is divided into two rank: the first rank civilian; the second rank civilian. The first level of civilian must have a college degree, The second rank civilian degree limit, But can never be entered in the first grade civilian. In 1890 the British government to adjust the first rank and second rank classification method, Restrict the number the first rank, And the second rank is divided into three levels. So the British civil service a total of four class rank, the administrative level, execution level, clerical, assistant instrument.

In mid twentieth Century, the number of British civil servants expanded rapidly. Especially after the Second World War, great changes have taken place in Britain's domestic situation, these changes have great influence on current development of the civil service system. The Second World War promoted the great progress of science and technology; the scientific and technological revolution not only changed the social structure, but also changed the structure of talent. Due to the special background of the war, the government controls the economy of the whole country. So the government needs to hire a number of civil servants with professional economic knowledge to manage the country. In order to gradually adapt to the new situation and new tasks, the most prominent reform of this period was the addition of horizontal divisions to the classification of civil service tastes, that is, outside the administrative categories, professional and technical personnel were added.

In 1950, British civil servants were divided into the following categories: industrial and non-industrial workers; authorized strength and non-authorized strength; general administrative staff and professional and technical personnel. Industrial workers mainly refers to the Ministry of Defense-owned military plants and naval docks, postal system staff, and in the research unit of the technical staff. Industrial workers is divided into 10 categories, have their own special wage level. Non-industrial workers, refers to the office of the executive instruments, administrative and professional management personnel, as well as diplomatic and consular staff.

Authorized strength and non-authorized strength. Authorized strength staff refers to those who enjoy retirement benefits in various government departments. Non-authorized strength, also known as non-column and other personnel, refers to the Department of temporary employment or employment of personnel, their treatment and conditions of service are different from the authorized strength.

General administrative staff and professional and technical personnel. General administrative staff is divided into administrative, economic, intelligence, statistics and other categories, the conditions of service by the Ministry of Finance unified provisions, also known as "the Ministry of Finance level of civil servants."

Professional and technical personnel are divided into two categories of science and technology, the general conditions of service by the ministries, also known as "various departments." Although this stage of reform has increased the horizontal division, but did not fundamentally change the civil service "generalist" and "closed" features, the number of professional and technical categories is still minimal.

\subsection{Gradual Transition to Give Priority to with Generalist Specialist Auxiliary Selection Mechanism}

In 1964 the Fulton reform strengthened the role of experts, but did not fundamentally change the "generalist" structure. Put forward a series of reform measures, "Fulton report" put forward.

First, the administration should be professional. Financial and social administrators must be qualified for their professional knowledge, and reading classical literature can not serve as a condition for civil servants.

Second, weaken the "generalist" decision-making. The Fulton Report makes the following recommendations: 1, Abolish the organizational structure in which professionals are subject to administrative and they can not be leaders. 2, To set up planning units to elevate government work to the level of planning work and policy research, and plan units to study long-term plans and examine whether daily administrative work meets the requirements of such plans. 3, Allowing ministers to take several private secretaries with expertise, weakening the influence of the generalist on the ministers, who can provide different views and recommendations from other civil servants and make ministerial decisions more proactive.

Third, change the "closed" to "open", absorbing all kinds of talent. Put forward that not only it is necessary to eliminate the 
horizontal classification of administrative and technical expertise, but also to change the upper and lower levels of the vertical classification, to achieve a bottom-up unity of the civil service classification structure, including all non-industrial sectors, so that all kinds of civil servants become a whole.

Fourth, establish specialized schools for the training of civil servants. The establishment of civilian schools, the professional knowledge training of the administrative staff at all levels and to set up administrative management courses for professional and technical personnel is very meaningful.

In 1971, the reform of the civil service classification system in the UK further expanded the categories of civil servants, and the classification of professional and administrative staff was developed into 10 categories. The increasingly complex structural evolution shows that the British civil service classification system is gradually approaching the classification of jobs.

Table 1. British rank classification system (after 1971).

\begin{tabular}{lll}
\hline Position Groups & Grades & Ranks \\
\hline & Administration & 10 \\
& Intelligence & 6 \\
General class & Economy & 4 \\
& Statistics & 4 \\
& Writer & 5 \\
& Communication & 2 \\
Science class & Science & 8 \\
Professional skill class & Expertise & 5 \\
& Books and newspapers, graphic staff & 5 \\
Training class & Sea service & 5 \\
Law class & & 6 \\
Police class & & 3 \\
Secretarial class & & 9 \\
Social security class & & 10 \\
Data processing class & & 2 \\
Investigation and study & Social science research & 3 \\
class & Resource planning survey & 5 \\
\hline
\end{tabular}

\subsection{The British Civil Service Classification System Development Path}

From the point of development history, the classification system of British civil servants was based on the rank classification, and gradually developed the position classification. Such a development path is that, at the beginning of the establishment of the civil service, social development is relatively backward and social affairs are not so complicated. But with the arrival of scientific and technological revolution, significant improvement of economic level and continuous development of the community, we need professionals to indicate the country. Therefore, professional and technical personnel gradually develop and have more speaking right. In the future, with the further increase of productivity and more sophisticated production technology, we will need more and more professionals to engage in the civil service jobs, eventually forming a pattern which "generalist" and "professionals" co-manage the country.

\section{British and Chinese Civil Servants Classification System Comparison}

Fig. 1 and Table 1 are the Chinese civil servant classification system and the British civil service classification system. It can be seen that Chinese civil servant classification system is simpler than British civil servant classification system. This is because national conditions in China have a greater difference than that in Britain. Firstly, the development history is different. The development of British civil service system has been going on for about two centuries, and the cadre-personnel system in china is only about 60 years. This is the important reason why the classification of civil servant system in china is not perfect. Secondly, the area is different. China has a vast territory and a large population while the United Kingdom has a small pocket and a small population. It requires china civil servant classification system more flexibility and elasticity, if the provisions are too detailed, the whole system may be stiff. Therefore, the civil servant classification system should adapt to national conditions, and develop the appropriate system according to the needs of their country.

\subsection{Group Contrast Analysis}

From the perspective of the division of position group, in china civil service position group is based on the requirements of the actual needs and subdivision, and separate the other groups from the integrated management category such as professional technical and administrative law enforcement class is separated from integrated management class, and then constantly refining to meet the needs of the society. Due to the long history of Britain civil servants, its evolution of position group is a gradual process. The position of Britain is now detailed but not invariable. With the continuous development of society, it can be subdivided according to the actual need.

From perspective position group consist of staff; species of china's comprehensive management is make up body of china's civil servant classification. Particularly point out, in china, the staff of party situation is also civil servant. This is different from eastern any of country. As china constitution clearly establish the leading status of the communist party in country political while clearly put forward China's system of multi-party cooperation and political consultation under the leadership of the communist party will exist and develop for a long time. and develop for a long time. Put work of party into the civil servant scope is according laws. This manner is match china chart, this is to seek truth from fact. The rest of staff exclude Party the same as the UK. Meaning is not big, don't comparison at this.

\subsection{Grade Analysis of the Contrast}

From perspective classification of grade, division of the position group while divide grade. Yet this is not accurate divide grade. In order to comprising, we are treating as this is divide grade. Actually, divide grade is elaborating the divide position group. In UK three position group including 
comprehensive species and special species and investigation species has elaborated in the grade. Every grade match rank. And the ranks match the wage. According to this consideration, divide position group, and then match the wage, so the divide grade is reasonable. China hasn't classification, because of china civil servant rank is different from UK. for example, special species and investigation species has elaborate divided, and has the same rank, every rank has every different event, it may be easy or difficult, the wage according to the work of degree easy or hard.

\subsection{Rank of Comparative Analysis}

From the theory of class of position, not UK class of position is unified grading, but defined for each of the professional ranks. In china, the class of position is unified grading. All the civil servant promote in this class of position. The coin has two sides. The class of position in England is advantage for foster special person. Yet this is disadvantage mobility talent, Time will be conducive to the cultivation of professional talent. The rank classification system of our country is conducive to the flow of talent. Because where is a system of rank. With the rank of position change move together. The disadvantage is that frequent flows, is not conducive to the industry and the work of this position are familiar with.

\section{The Path of the Future Development of China's Civil Service Classification Method}

\subsection{China Is Not Suitable for Political Appointee - Officer}

Political appointee and officer is points method of western civil service classification system, This classification method is based on the political system of "separation of three powers". The political appointee is a product of western political parties, Is produced by political election or appointment, And with political parties and the cabinet. Officer remain politically neutral, Not with political parties and with the cabinet.

China is not suitable for this kind of "two officer extremely way" rule of thirds. First, China's political system was completely different with the west, And "two officer extremely way" is in line with the western political background. Second, Chinese officials must have a basic experience, basic experience of the work is equal to the officer, And with the constant promotion of personal position, When the regional chief is equivalent to the western political appointee. Finally, China does not exist politically neutral, The communist party of China always lead the Chinese people to victory.

\subsection{Classification Method in Psychology in the Future}

The classification and management of civil servants comes down to one point is for the management of people. Only the people manage the affairs in an orderly way to proceed. People at work will inevitably have a variety of resistance, Or the job pressure, Or is it the complicated interpersonal relationship and so on. For this reason, Because of position classification is not suitable, Do not do men's management style, In the final analysis is that there is no consider what are the requirements for the position for psychological quality aspect. Therefore, at the time of the position classification also want to consider the position of psychological pressure, At the same time in terms of choice of choose and employ persons, match the position, This classification is the human nature, Is also effective.

\subsection{In the Position Is Given Priority to Taste Is Complementary in the Way to Reform}

British civil servants on taste classification system of position classification system gradual development. That's because the development of the science and technology is the post is detailed and professional. Therefore in the appointment of some "generalists" to govern is unrealistic. So as the civil service classification system in China to give priority to in order to position the points and to taste relies on classification of civil servants classification system development. Combine the two can play a bigger role.

\section{Conclusion}

The development of China's civil service classification system started relatively late, but also obtain larger effect, China's civil service system was conducted in a methodical, Of course there are also many problems and deficiencies, This is need a slowly process of development and continuous improvement. Evaluation standard of system of a good or bad depends on whether suits you, Can promote the development, Today, China's civil service system is relatively appropriate. Therefore the system developing in the future, Also always stick to the development of suitable guidance, in order to achieve better development effect.

\section{References}

[1] Qing-huan Shi. Europe and the United States the basic characteristics of the civil service classification system and its historical evolution $[\mathrm{J}]$. Journal of northeast normal university, 2000 01: 9-16.

[2] Bai-lin Zhang. The civil servant law of the People's Republic of China [M]. China personnel press, 2012.

[3] Pei Guo. The evolution of the United States, and British civil service system of classified management and its enlightenment [J]. Journal of Chinese administrative management, 2009.

[4] Da-wei Zhang, Wang gang. Try to talk about the position classification system of enlightenment to our country civil servants classification system [J]. Journal of empirical analysis.

[5] Bi-qiang Liu. American and British civil service system of classified management evolution and its enlightenment $[\mathrm{J}]$. Journal of China petroleum university (social science edition), 2013, 11: 51-57. 
[6] Li-mei Gu. Britain, the United States civil service classification system's development and enlightenment [J]. Journal of the Chinese party and government cadres, BBS, 2016, 09: 24-27.

[7] Yun-gui Shi. "political and administrative dichotomy" western enlightenment on classified management of civil servants in our country, new idea and theory of the prevention and control of corruption "head" [J]. Journal of sichuan university (philosophy and social sciences edition), 2013 01: 26-32.

[8] Shi-ming Song. Innovation of China's civil service system of classified management legislation thought [J]. Journal of Chinese administrative management, 2003, 05: 15 to 17.
[9] Yu-ming Hao. Classification of civil servant management practice and experience for reference, based on the analysis of shenzhen civil service classification reform [J]. Journal of the Chinese party and government cadres, BBS, 2016, 09: 28 and 33.

[10] Suo liang lv, Chen Jiang. Promote the civil service classification starting time $[\mathrm{J}]$. Journal of the Chinese party and government cadres BBS, 2016, 09: 21-23. 